\title{
Problem Based Learning (PBL): Promoting soft skills in accounting education
}

- This new study aims to share our experience in teaching an accounting course using a teaching method called problem-based learning (PBL). In 2020, two sections of the introduction to information technology (IT) online classes of undergraduate accounting are using the PBL approach. The sample has 71 students. Based on accounting case studies, the idea is to engage the students to solve problems required using information technology tools. Here are the five steps for implementation of PBL: (a) Identify the problem \& plan the solution develop problem-solving skills (b) Identity what they need to know to solve the problem and do individual research. Next, share the findings in a discussion forum using a personal video hosted in YouTube server develop collaboration skills (c) Through research and data analysis, learn how to solve the problem using Excel(C) and BI tools - develop collaboration and problem-solving skills (d) Written/oral presentation using SlideServer and YouTube server online discussion, and peer-assessment/self-assessment of the solution presented -develop collaboration, critical thinking and communication skills (e) Discuss ethical concepts regarding the case studies develop critical skills. We collected grades and perceptions of students, from both classes, regarding the relevance of the soft skills for their careers and personal life.

- Instructors can make non-cognitive instruction part of their course design. PBL may help to promote soft skills 